\title{
Association between air pollution and COVID-19 mortality and morbidity
}

\author{
Karolina Semczuk-Kaczmarek ${ }^{1}$ (1) - Anna Rys-Czaporowska ${ }^{1} \cdot$ Janusz Sierdzinski $^{2} \cdot$ Lukasz Dominik Kaczmarek $^{3}$. \\ Filip Marcin Szymanski ${ }^{4}$ Anna Edyta Platek ${ }^{5}$
}

Received: 6 May 2021 / Accepted: 20 August 2021 / Published online: 12 October 2021

(c) The Author(s) 2021

\begin{abstract}
Coronavirus disease (COVID-19) pandemic is affecting the world unevenly. One of the highest numbers of cases were recorded in the most polluted regions worldwide. The risk factors for severe COVID-19 include diabetes, cardiovascular, and respiratory diseases. It has been known that the same disease might be worsened by chronic exposure to air pollution. The study aimed to determine whether long-term average exposure to air pollution is associated with an increased risk of COVID-19 cases and deaths in Poland. The cumulative number of COVID-19 cases and deaths for each voivodeship (the main administrative level of jurisdictions) in Poland were collected from March 4, 2020, to May 15, 2020. Based on the official data published by Chief Inspectorate of Environmental Protection voivodeship-level long-term exposure to main air pollution: $\mathrm{PM}_{2.5}, \mathrm{PM}_{10}, \mathrm{NO}_{2}, \mathrm{SO}_{2}, \mathrm{O}_{3}$ (averaged from 2013 to 2018) was established. There were statistically significant correlation between COVID-19 cases (per 100,000 population) and annual average concentration of $\mathrm{PM}_{2.5}\left(R^{2}=0.367\right.$, $p=0.016), \mathrm{PM}_{10}\left(R^{2}=0.415, p=0.009\right), \mathrm{SO}_{2}\left(R^{2}=0.489, p=0.003\right)$, and $\mathrm{O}_{3}\left(R^{2}=0.537, p=0.0018\right)$. Moreover, COVID-19 deaths (per 100,000 population) were associated with annual average concentration of $\mathrm{PM}_{2.5}\left(R^{2}=0.290, p=0.038\right), \mathrm{NO}_{2}$ $\left(R^{2}=0.319, p=0.028\right), \mathrm{O}_{3}\left(R^{2}=0.452, p=0.006\right)$. The long-term exposure to air pollution, especially $\mathrm{PM}_{2.5}, \mathrm{PM}_{10}, \mathrm{SO}_{2}$, $\mathrm{NO}_{2}, \mathrm{O}_{3}$ seems to play an essential role in COVID-19 prevalence and mortality. Long-term exposure to air pollution might increase the susceptibility to the infection, exacerbates the severity of SARS-CoV-2 infections, and worsens the patients' prognosis. The study provides generalized and possible universal trends. Detailed analyzes of the phenomenon dedicated to a given region require taking into account data on comorbidities and socioeconomic variables as well as information about the long-term exposure to air pollution and COVID-19 cases and deaths at smaller administrative level of jurisdictions (community or at least district level).
\end{abstract}

Keywords Air pollution · SARS-CoV-2 · COVID-19 · Cardiovascular disease

Karolina Semczuk-Kaczmarek

karolina.semczuk-kaczmarek@wum.edu.pl

1 1st Department of Cardiology, Medical University of Warsaw, Banacha 1A St., 02-097 Warsaw, Poland

2 Department of Medical Informatics and Telemedicine, Medical University of Warsaw, Warsaw, Poland

3 Faculty of Building Services, Hydro and Environmental Engineering, Warsaw University of Technology, Warsaw, Poland

4 Departament of Civilization Diseases, Faculty of Medicine, Collegium Medicum, Cardinal Stefan Wyszyński University in Warsaw, Warsaw, Poland

5 Department of General and Experimental Pathology, Medical University of Warsaw, Warsaw, Poland

\section{Introduction}

Coronavirus disease (COVID-19) has appeared in Wuhan (China) in December 2019 [1]. Owing to the rapid geographic transmission of severe acute respiratory syndrome coronavirus 2 (SARS-CoV-2), the World Health Organization declared the outbreak of a Public Health Emergency of International Concern on January 30, 2020. Up to May 21, 2020, more than 4.89 million cases of COVID-19 were reported, resulting in 323 256 deaths in 216 countries [2]. The symptoms caused by the SARS-CoV-2 infections can range from mild (even asymptomatic) through fever, dry cough, fatigue, shortness of breath, up to pneumonia, and acute respiratory distress syndrome (ARDS). The clinical manifestation depends on the patient's age, physical condition, and comorbidities. The Centers for 
Disease Control and Prevention 's list of risk factors for severe COVID-19 include diabetes, heart diseases, and chronic airway diseases (i.e., asthma, lung cancer, and chronic obstructive pulmonary disease) [3]. Most of those risk factors may be triggered by chronic exposure to air pollution.

Air pollution consists of volatile organic compounds, small particulate matter $\left(\mathrm{PM}_{2.5}, \mathrm{PM}_{10}\right)$, and gases [nitric dioxide $\left(\mathrm{NO}_{2}\right)$; carbon monoxide $(\mathrm{CO})$; ground-level ozone $\left(\mathrm{O}_{3}\right)$, sulfur dioxide $\left(\mathrm{SO}_{2}\right)$ ] derived from industrial emissions, vehicular traffic, or indoor pollutants. The larger mass of chemical compounds in air pollution is made of semi-volatile or nonvolatile compounds, in particular, the group of polycyclic aromatic hydrocarbons (PAHs). It is worthy to underline that exposure to PAHs (emissions from motor vehicles, industrial plants, power generation plants, waste incinerators, and open burning) has been linked with lung cancer, cardiovascular disease and poor fetal development. Thus, if such data are recorded commonly, it is recommended to use it. In the described case, the most complete and available data concerned the parameters listed at the beginning of the paragraph. It has been estimated that every year $\approx 7$ million people worldwide die from exposure to polluted air [4]. Almost half of them will die of ischemic heart disease or stroke attributed to exposure to air pollution. Making air pollution more significant than any other major modifiable cardiovascular risk factors (smoking, hypertension, hyperlipidemia, and diabetes mellitus) [4]. For these reasons, we hypothesize that air pollution may worsen the prognosis of COVID-19 patients by exacerbating underlying cardiovascular or respiratory diseases and suppressing immune responses [5].

Poland is one of the most polluted countries in the European Union (EU). Out of the 50 most polluted cities in the EU, 33 are in Poland. Poland's main problem is excessive concentration of tropospheric ozone in summer and $\mathrm{PM}_{10}$ and benzo(a)pyrene in winter [6]. It has been estimated that due to exposure to air pollution, the life expectancy of an average Polish citizen is shortened by around 9 months, and 48 thousand people die prematurely every year due to air pollution $[7,8]$. The current study aimed to assess if longterm average exposure to air pollution is associated with an increased risk of COVID-19 cases and deaths in Poland.

In the study, we take into account, the administrative division of Poland for sixteen voivodships. Voivodships is the highest level administrative division of Poland, corresponding to a province or state in many other countries.

\section{Methods}

\section{COVID-19 cases and deaths in Poland}

The official data of SARS-CoV-2 infections and deaths by voivodeships in Poland are published daily by the Polish
Ministry of Health [9]. All cases are diagnosed as positive based on the polymerase chain reaction tests for SARSCoV-2. We collected the cumulative number of cases and deaths for each voivodeship in Poland from March 4, 2020 (first confirmed COVID-19 case in Poland) up to May 15, 2020. Individual-level data of COVID-19 deaths and cases in Poland are currently not available.

\section{Exposure to air pollution}

The effect of chronic exposure tends to be stronger than relationships with short-term exposure $[10,11]$. Therefore, we calculated voivodeship-level long-term exposure to main air pollution: $\mathrm{PM}_{2.5}, \mathrm{PM}_{10}, \mathrm{NO}_{2}, \mathrm{SO}_{2}, \mathrm{O}_{3}$ (averaged from 2013 to 2018). Chief Inspectorate of Environmental Protection publishes the official data about exposure, and they are the results of measurements by air pollution monitoring stations throughout the 16 voivodeships in Poland. These stations belong mainly to the Chief Inspectorate of Environmental Protection, as well as to research institutes and other organizations cooperating within the Chief Inspectorate of Environmental Protection. The currently available official data include the annual average level of $\mathrm{PM}_{2.5}, \mathrm{PM}_{10}, \mathrm{NO}_{2}, \mathrm{SO}_{2}$, $\mathrm{O}_{3}$, updated yearly from 2013 to 2018 [12].

According to the Reports of the State of Environment in Poland published by Chief Inspectorate of Environmental Protection upper limit of the annual average concentration of air pollution in Poland are dependent on the kind of pollution. Thus, upper limit for annual average concentration of $\mathrm{PM}_{2.5}, \mathrm{PM}_{10}, \mathrm{NO}_{2}, \mathrm{SO}_{2}, \mathrm{O}_{3}$ are $25 \mu \mathrm{g} / \mathrm{m}^{3}, 40 \mu \mathrm{g} / \mathrm{m}^{3}, 40 \mu \mathrm{g} /$ $\mathrm{m}^{3}, 125 \mu \mathrm{g} / \mathrm{m}^{3}, 120 \mu \mathrm{g} / \mathrm{m}^{3}$, respectively (based on the European Parliament and Council Directive 2008/50/EC) [12]. Reports of the State of Environment in Poland provide the number of days with $\mathrm{O}_{3}$ concentration exceeding the upper limit $\left(120 \mu \mathrm{g} / \mathrm{m}^{3}\right)$.

\section{Statistical methods}

Voivodeship-level COVID-19 prevalence rates were defined as the ratio of COVID-19 incidence to voivodeship level population size. For further detailed analyses, COVID-19 cases (per 100,000 population) and deaths (per 100,000 population) in each voivodeship were calculated. The association between all assessed parameters and COVID-19 prevalences and mortality was assessed using Spearman's correlation. Although individual-level data would have allowed a more rigorous statistical analysis, individual-level data on COVID-19 death is currently unavailable. Forward stepwise multivariate logistic regression models were created to identify the independent predictors of COVID-19 cases and deaths. A $p$ value $<0.05$ was considered statistically significant. Statistical processing of data was made using SPSS v. 21 software (SPSS Inc., Chicago, USA). 


\section{Results}

As of May 15, 2020, there were 18,016 laboratory-confirmed COVID-19 cases and 907 deaths. The highest number of COVID-19 cases was in Silesian ( $n=4994$ cases), and Mazovian Voivodeship $(n=2930)$; the lowest was in Lubusz ( $n=92$ cases) and Warmian-Masurian Voivodeship ( $n=170$ cases). Similarly, the highest number of COVID-19 death was in Mazovian $(n=231$ deaths) and Silesian Voivodeship $(n=172)$; the lowest was in Lubusz $(n=0)$ and Warmian-Masurian Voivodeship ( $n=1$ case).

From 2013 to 2018, the highest average concentrations of $\mathrm{PM}_{2.5}$ and $\mathrm{PM}_{10}$ were in Silesian $\left(30.27 \mu \mathrm{g} / \mathrm{m}^{3}\right.$ and $42.35 \mu \mathrm{g} / \mathrm{m}^{3}$, respectively), Lesser Poland (30.87 $\mu \mathrm{g} /$ $\mathrm{m}^{3}$ and $40.18 \mu \mathrm{g} / \mathrm{m}^{3}$, respectively) and Lodz Voivodeship (26.71 $\mu \mathrm{g} / \mathrm{m}^{3}$ and $37.99 \mu \mathrm{g} / \mathrm{m}^{3}$, respectively). In addition, these values exceed the upper limit for annual average concentration on $\mathrm{PM}_{2.5}$ and $\mathrm{PM}_{10}$. The lowest average concentration of $\mathrm{PM}_{2.5}$ and $\mathrm{PM}_{10}$ was in Warmian-Masu$\operatorname{rian}\left(15.78 \mu \mathrm{g} / \mathrm{m}^{3}\right.$ and $25.45 \mu \mathrm{g} / \mathrm{m}^{3}$, respectively), Pomeranian $\left(16.88 \mu \mathrm{g} / \mathrm{m}^{3}\right.$ and $23.66 \mu \mathrm{g} / \mathrm{m}^{3}$, respectively), West Pomeranian Voivodeship $\left(17.22 \mu \mathrm{g} / \mathrm{m}^{3}\right.$ and $24.61 \mu \mathrm{g} / \mathrm{m}^{3}$, respectively).

The highest concentration of $\mathrm{NO}_{2}$ was noted in Lesser Poland $\left(40.25 \mu \mathrm{g} / \mathrm{m}^{3}\right), \mathrm{SO}_{2}$ concentration in Silesian $\left(55.53 \mu \mathrm{g} / \mathrm{m}^{3}\right)$, and the highest number of days with $\mathrm{O}_{3}$ concentration exceeding the upper limit was in Lower Silesia Voivodeship (8 days). Podlaskie Voivodeship had the lowest concentration of $\mathrm{NO}_{2}\left(11.73 \mu \mathrm{g} / \mathrm{m}^{3}\right), \mathrm{SO}_{2}(10.21 \mu \mathrm{g} /$ $\mathrm{m}^{3}$ ), and the lowest number of days with $\mathrm{O}_{3}$ concentration exceeding the upper limit 30 days).

We have observed statistically significant correlation between COVID-19 cases (per 100,000 population) and annual average concentration of $\mathrm{PM}_{2.5}$ (coefficient of determination, $\left.R^{2}=0.367, p=0.016\right), \mathrm{PM}_{10}\left(R^{2}=0.415\right.$, $p=0.009), \mathrm{SO}_{2}\left(R^{2}=0.489, p=0.003\right)$, and $\mathrm{O}_{3}\left(R^{2}=0.537\right.$, $p=0.0018)$. Moreover, there was a significant correlation between COVID-19 deaths (per 100,000 population) and
$\mathrm{PM}_{2.5}\left(R^{2}=0.290, p=0.038\right), \mathrm{NO}_{2}\left(R^{2}=0.319, p=0.028\right)$, $\mathrm{O}_{3}\left(R^{2}=0.452, p=0.006\right)$ concentrations (Table 1$)$. Summary of average concentration of air pollution, COVID-19 cases, and death (per 100,000 population) in voivodeships in Poland is presented in Fig. 1.

\section{Discussion}

The observed correlation between exposure to air pollution and COVID-19 cases and deaths in Poland are consistent with previously published studies describing these associations in other countries [13]. The first nationwide study of the relationship between historical exposure to air pollution exposure and the COVID-19 death rate was conducted in the United States by Wu et al. [13]. They analyzed data for county-level long-term exposure to $\mathrm{PM}_{2.5}$ (averaged from 2000 to 2016) on county-level COVID-19 deaths. They found that an increase of at least $1 \mu \mathrm{g} / \mathrm{m}^{3}$ in long-term average $\mathrm{PM}_{2.5}$ was associated with an $8 \%$ increase in the COVID-19 death rate-(RR 1.08; 95\% CI 1.02-1.15). They also observed that other factors might be predictors of higher risk of COVID-19 mortality rate-population density, rate of hospital beds, days since first COVID-19 case reported and less obvious-median household income, less than high school education, and Black Americans. The mechanism that may explain the relationship between air pollution and viral outcomes is that $\mathrm{PM}_{2.5}$ exposure is associated with many of the cardiovascular and respiratory comorbidities that increase the severity and risk of death in COVID-19 patients [14]. The immune responses might be suppressed by exposure to pollution, which leads to worse prognosis [15].

At the early stage of the pandemic, Italy was the country with the highest number of COVID-19 infections in Europe [16]. The outbreaks focused in North Italy-Po Valley, and the cities of Lodi, Cremona, and Bergamo. Conticini et al. noted that these cities are in the five Italian cities with the highest pollution emissions due to a high density of factories, traffic, and intensive agriculture [16]. Specific
Table 1 Correlation between COVID-19 cases and deaths (per 100,000 population) and annual average concentration of air pollution

\begin{tabular}{|c|c|c|c|c|c|}
\hline \multirow[t]{2}{*}{ Parameter } & \multirow[t]{2}{*}{$\begin{array}{l}\text { Value } \\
(\text { mean } \pm S D)\end{array}$} & \multicolumn{2}{|c|}{$\begin{array}{l}\text { COVID- } 19 \text { cases } \\
\text { (per } 100,000 \text { popula- } \\
\text { tion) }\end{array}$} & \multicolumn{2}{|c|}{$\begin{array}{l}\text { COVID-19 } \\
\text { deaths } \\
\text { (per 100,000 } \\
\text { population) }\end{array}$} \\
\hline & & $R^{2}$ & $p$ & $R^{2}$ & $p$ \\
\hline $\mathrm{PM}_{2.5}\left(\mu \mathrm{g} / \mathrm{m}^{3}\right)$ & $22.90 \pm 4.49$ & 0.367 & 0.016 & 0.290 & 0.038 \\
\hline $\mathrm{PM}_{10}\left(\mu \mathrm{g} / \mathrm{m}^{3}\right)$ & $31.40 \pm 5.48$ & 0.415 & 0.009 & 0.252 & 0.056 \\
\hline $\mathrm{SO}_{2}\left(\mu \mathrm{g} / \mathrm{m}^{3}\right)$ & $21.70 \pm 10.87$ & 0.489 & 0.003 & 0.169 & 0.127 \\
\hline $\mathrm{NO}_{2}\left(\mu \mathrm{g} / \mathrm{m}^{3}\right)$ & $23.58 \pm 7.82$ & 0.262 & 0.051 & 0.319 & 0.028 \\
\hline $\begin{array}{l}\mathrm{O}_{3} \text { (the number of days with } \mathrm{O}_{3} \text { concentration } \\
\text { exceeding the upper limit }\left(120 \mu \mathrm{g} / \mathrm{m}^{3}\right)\end{array}$ & $17.16 \pm 6.62$ & 0.537 & 0.0018 & 0.452 & 0.006 \\
\hline
\end{tabular}

$R^{2}$ coefficient of determination, $S D$ standard deviation 
A
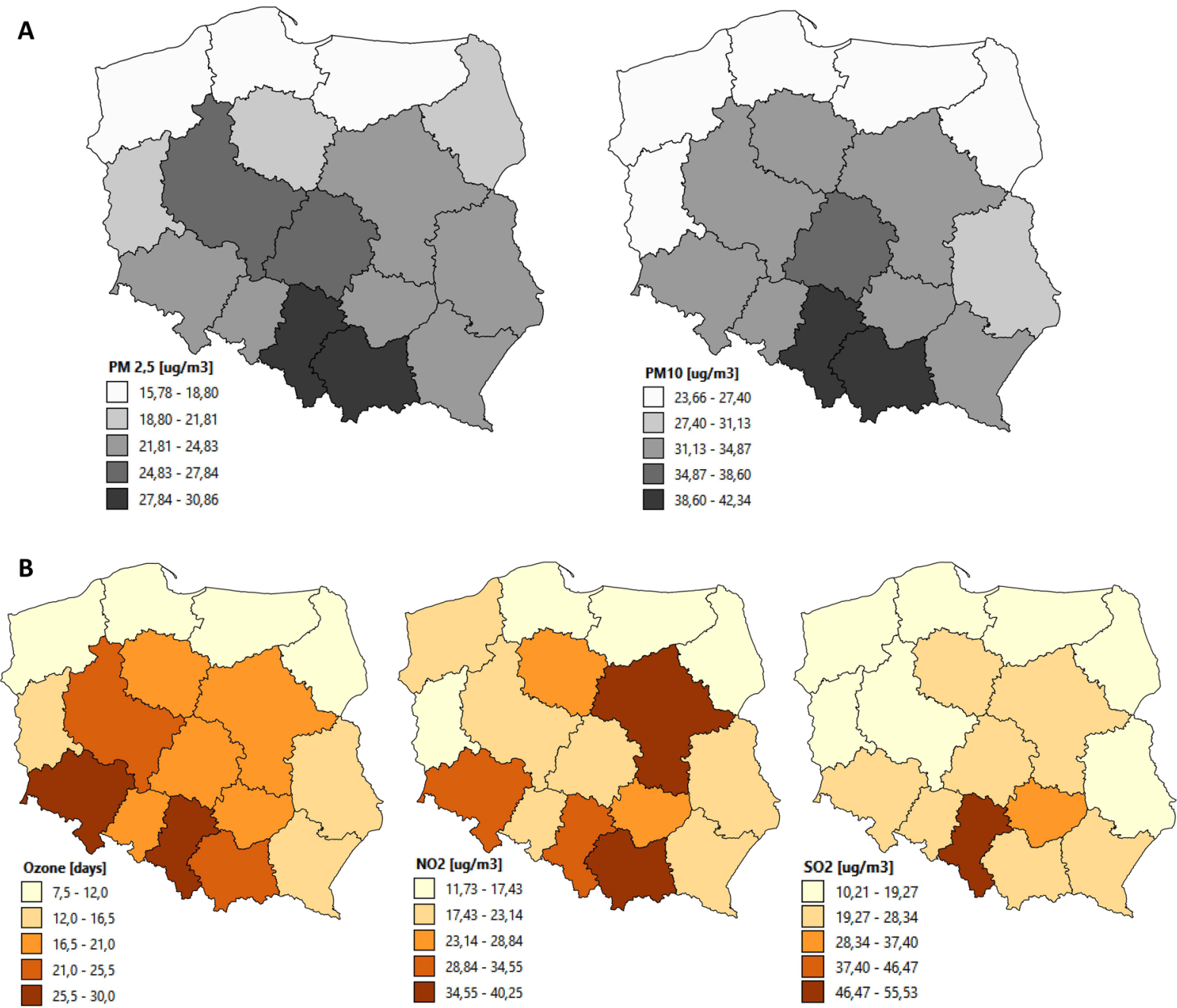

C

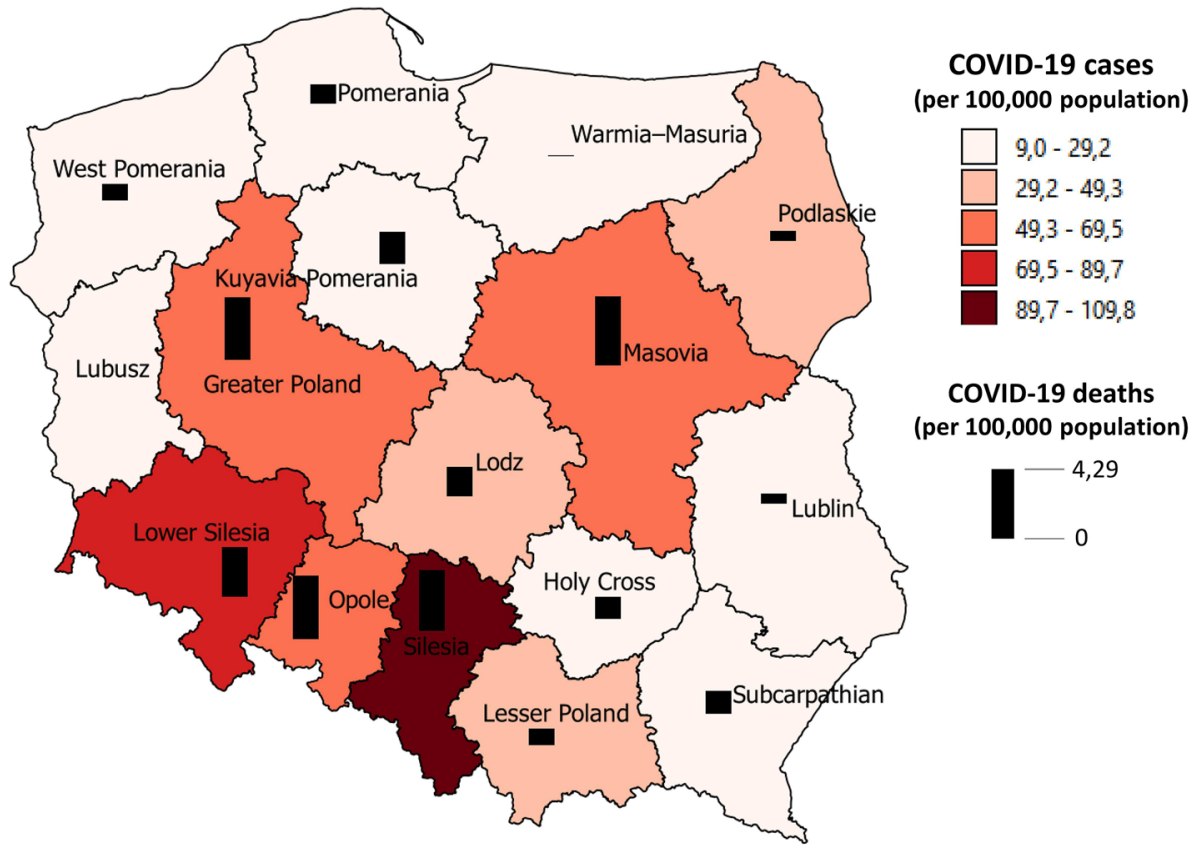


4Fig. 1 Summary of the average concentration of air pollution, COVID-19 cases, and death in voivodeships in Poland (A concentration of $\mathrm{PM}_{2.5} ; \mathrm{PM}_{10} ; \mathbf{B}$ concentrations of $\mathrm{O}_{3}, \mathrm{NO}_{2}, \mathrm{SO}_{2}$; C, COVID19 cases and death per 100,000 population)

topography (plain surrounded by the Alps), climatic features (frequent episodes of climatic inversion) cause the stagnation of pollutants. The concentrations of $\mathrm{PM}_{2.5}$ over this region reached very high values, which are similar to those characterizing the Hubei province in China, where the first COVID-19 cases were recognized.

In addition, the case fatality for COVID-19 in North Italy was $12 \%$, and was significantly higher as compared to $4.5 \%$ in the rest of Italy [16]. The authors suggest that observed high prevalence and COVID-19 mortality might be secondary to long-term exposure to air pollution. Previous studies report that long-term exposure to air pollution impairs cilia and upper airways defenses, promotes a chronic inflammatory state, increases the risk of chronic respiratory disease [11]. Another analysis also confirmed that long-term airquality data $\left(\mathrm{NO}_{2}, \mathrm{O}_{3}, \mathrm{PM}_{2.5}\right.$, and $\left.\mathrm{PM}_{10}\right)$ significantly correlated with cases of COVID-19 in up to 71 Italian provinces [17].

Another study found that COVID-19 mortality was associated with $\mathrm{NO}_{2}$ concentration [18]. It has been observed that 78\% of fatality cases $(n=3487)$ occurred in North Italy and central Spain regions with the highest NO2 concentration. In the previous studies, elevated exposure to $\mathrm{NO}_{2}$ was connected with hypertension, cardiovascular, chronic obstructive pulmonary disease (COPD), and lung injury [18]. It was also described the destroying impact of longterm $\mathrm{NO}_{2}$ exposure on epithelial cells in the lung and promoting the synthesis of proinflammatory cytokines from airway epithelial cells.

Another research group using annual indices of air quality analyzed the correlation between air pollution and SARSCoV-2 morbidity and mortality [19]. It found significant positive correlations between air quality variables and COVID19 cases, with higher rates of COVID-19 infection in areas with high $\mathrm{NO}_{2}$ and $\mathrm{CO}$ concentration. Higher mortality was also correlated with high $\mathrm{PM}_{2.5}, \mathrm{CO}$, and $\mathrm{NO}_{2}$ concentration [19]. Similarly, a cross-sectional analysis conducted by Yao et al. showed positive correlations between $\mathrm{NO}_{2}$ pollution levels and COVID-19 transmission rates in the cities in Hubei province, China [20]. In addition, they observed that increased concentrations of $\mathrm{PM}_{2.5}$ and $\mathrm{PM}_{10}$ were linked to higher death rates from COVID-19 $(p=0.011$ and $p=0.015$, respectively) [21]. Nevertheless, some researchers supposed that the atmosphere rich in air pollutants might promote a longer permanence of the viral particles in the air and facilitate the spreading of SARS-CoV-2 [22].

The observed association might be linked to low-grade pulmonary damage and inflammation caused by air pollution
[23]. There is a hypothesis that long-term exposure to air pollution might increase the susceptibility to the infection and impair pulmonary defense mechanisms [23, 24]. Some hypothesize that exposure to air pollution and SARSCoV-2 is a "double-hit" to the lungs and lead to acute lung injury [8]. $\mathrm{PM}_{2.5}$ penetrates the peripheral air spaces and, through the interaction with the lung renin-angiotensin system (RAS) may facilitate viral infection [8]. It is described that angiotensin-converting enzyme 2 (ACE-2) expressed at the alveolar level is a co-receptor for the viral entry of SARS-CoV-2 through interaction with viral spike proteins (VPS) [25]. Patients chronically exposed to high levels of $\mathrm{PM}_{2.5}$ overexpress ACE-2. High pulmonary expression of ACE-2 correlates with susceptibility to SARS-CoV-2 infection. SARS-CoV-2 binding to ACE-2 might induce deficient anti-inflammatory action leading to acute lung injury [25].

\section{Limitations}

No studies were published concerning the impact of air quality in Central Europe on COVID-19 cases. Nevertheless, our study has some limitations. First, similarly to other studies nationwide, individual-level COVID-19 outcome data are unavailable at this time. At the time of preparing this study commonly available was the data on the number of COVID-19 cases and deaths at voivodships level (the main administrative level of jurisdictions in Poland). Such the data enable the derivation of important generalized and possible universal trends. We suggest that the data from smaller administrative level of jurisdictions (community or at least district level) will deliver more accurate information about the impact of local long-term exposure to air pollution and COVID-19 cases and deaths. This type of study should be designed in the future when more detailed information will be available. Detailed analyzes of the COVID-19 pandemic phenomenon dedicated to a given region requires taking into account data on comorbidities and socioeconomic variables as well as information about the long-term exposure to air pollution and COVID-19 cases and deaths at smaller administrative level of jurisdictions (community or at least district level). Secondly, confirmed COVID-19 cases probably are a supposed percent of the exact SARS-CoV-2 infection incidence rate because, in most cases, asymptomatic patients or patients with mild symptoms were not tested and remain unidentified [26]. Thirdly, highly polluted areas are characterized by higher rates of human interaction and international travelers, which facilitates the spreading of SARS-CoV-2 infection. An increase in COVID cases for 100,000 population might lead to a proportional increase in COVID mortality for 100,000 population. In our opinion, it is crucial to underline that our study and mentioned above articles describe the association between COVID-19 prevalence, mortality, and air pollution. We proposed that 
other factors widespread in these densely populated and highly industrialized areas like long-term exposure do air pollution, especially $\mathrm{PM}_{2.5}, \mathrm{NO}_{2}$, and $\mathrm{O}_{3}$ play an important role in COVID-19 mortality. We observed, that the highest number of COVID-19 cases and deaths per 100,000 populations were recorded in the most polluted voivodeships in Poland: Silesian, Lower Silesian, Masovian, Opole, Lodz, Greater Poland Voivodeships, whereas the lowest number was noted in voivodeships with better air quality: Lubusz, Warmian-Masurian, Podlaskie Voivodeships. We concluded that long-term exposure to air pollution, especially PM2.5, $\mathrm{PM} 10, \mathrm{SO} 2, \mathrm{NO} 2, \mathrm{O}_{3}$ seems to play an essential role in COVID-19 prevalences and mortality. The obtained results indicate the importance of further research using interdisciplinary data recorded at the lowest levels of regions division.

Last but not least, regression models (as used in this paper) in epidemiological research that involves air pollution are not perfect tools for assessing whether reducing exposure to air pollution will reduce the risk of harm to human [27]. This role is assigned for the traditional scientific method based on the testing predictive generalizations against data. It is worthy to underline that science should be completed (not substituted) by regression models [27].

Acknowledgements The authors would like to thank the anonymous reviewers for their valuable comments.

Author contributions KS-K, AEP, FMS contributed to the conception of the work. KS-K, AR-C, AEP, and LDK performed search and extracted data. JS and FMSZ conducted statistical analyses. KS-K, AR-C, AEP, FMS, and LDK drafted the manuscript and contributed to data acquisition, analysis, and interpretation. KS-K, AEP, FSM critically revised the manuscript and contributed to data interpretation. All authors provided the final approval and agreed to be accountable for all aspects of the work ensuring its integrity and accuracy.

\section{Declarations}

Conflict of interest The authors declare that they have no conflict of interest.

Ethical approval All procedures performed in studies involving human participants were in accordance with the ethical standards of the institutional and/or national research committee and with the 1964 Helsinki declaration and its later amendments or comparable ethical standards.

Informed consent The study was an observational study based on the generally available data (exposure to air pollution, number of COVID19 cases and deaths in Poland). No written informed consent to participate in the study was required.

Open Access This article is licensed under a Creative Commons Attribution 4.0 International License, which permits use, sharing, adaptation, distribution and reproduction in any medium or format, as long as you give appropriate credit to the original author(s) and the source, provide a link to the Creative Commons licence, and indicate if changes were made. The images or other third party material in this article are included in the article's Creative Commons licence, unless indicated otherwise in a credit line to the material. If material is not included in the article's Creative Commons licence and your intended use is not permitted by statutory regulation or exceeds the permitted use, you will need to obtain permission directly from the copyright holder. To view a copy of this licence, visit http://creativecommons.org/licenses/by/4.0/.

\section{References}

1. Martelletti L, Martelletti P (2020) Air pollution and the novel Covid-19 disease: a putative disease risk factor. SN Compr Clin Med 1-5. doi.org10.1007/s42399-020-00274-4.

2. https://www.who.int/emergencies/diseases/novel-coronavirus2019/events-as-they-happen. Accessed April 30, 2021

3. Wu C, Chen X, Cai Y et al (2020) Risk factors associated with acute respiratory distress syndrome and death in patients with coronavirus disease 2019 pneumonia in Wuhan, China. JAMA Intern Med 180:934-943

4. Kim JB, Prunicki M, Haddad F et al (2020) Cumulative lifetime burden of cardiovascular disease from early exposure to air pollution. J Am Heart Assoc 9(6): 014944

5. Brandt EB, Beck AF, Mersha TB (2020) Air pollution, racial disparities, and COVID-19 mortality. J Allergy Clin Immunol 146(1):61-63

6. http://www.gios.gov.pl/pl/aktualnosci/521-stan-srodowiska-wpolsce-raport-2018. Accessed April 30, 2021

7. Pikala M, Maniecka-Bryła I (2017) Fifteen-year mortality trends in Poland analysed with the use of standard expected years of life lost, 2000-2014. Sci Rep 7(1):8730

8. Frontera A, Cianfanelli L, Vlachos K et al (2020) Severe air pollution links to higher mortality in COVID-19 patients: the "double-hit" hypothesis. J Infect 81(2):255-259

9. https://www.gov.pl/web/koronawirus/wykaz-zarazen-koron awirusem-sars-cov-2. Accessed April 30, 2021

10. Di Q, Dai L, Wang Y et al (2017) Association of short-term exposure to air pollution with mortality in older adults. JAMA 318(24):2446-2456

11. Tsai DH, Riediker M, Berchet A et al (2019) Effects of shortand long-term exposures to particulate matter on inflammatory marker levels in the general population. Environ Sci Pollut Res Int 26(19): 19697-19704

12. https://powietrze.gios.gov.pl/pjp/archives. Accessed: April 30, 2021

13. Wu X, Nethery RC, Sabath MB et al (2020) Exposure to air pollution and COVID-19 mortality in the United States: a nationwide cross-sectional study. medRxiv. https://doi.org/10.1101/ 2020.04.05.20054502 (Preprint)

14. Ciencewicki J, Jaspers I (2007) Air pollution and respiratory viral infection. Inhal Toxicol 19(14):1135-1146

15. Becker S, Soukup JM (1999) Exposure to urban air particulates alters the macrophage-mediated inflammatory response to respiratory viral infection. J Toxicol Environ Health 57(7):445-457

16. Conticini E, Frediani B, Caro D (2020) Can atmospheric pollution be considered a co-factor in extremely high level of SARSCoV-2 lethality in Northern Italy? Environ Pollut 261:114465

17. Fattorini D, Regoli F (2020) Role of the chronic air pollution levels in the Covid-19 outbreak risk in Italy. Environ Pollut 264:114732

18. Ogen Y (2020) Assessing nitrogen dioxide (NO2) levels as a contributing factor to coronavirus (COVID-19) fatality. Sci Total Environ 726:138605

19. Pansini R, Fornacca D (2020) Initial evidence of higher morbidity and mortality due to SARS-CoV-2 in regions with lower air quality. medRxiv. https://doi.org/10.1101/2020.04.04.20053595 
20. Yao Y, Pan J, Liu Z, et al (2020) Ambient nitrogen dioxide pollution and spreadability of COVID-19 in Chinese cities. medRxiv. https://doi.org/10.1101/2020.03.31.20048595

21. Yao Y, Pan J, Liu Z, et al (2020) Temporal Association Between Particulate Matter Pollution and Case Fatality Rate of COVID19 in Wuhan, China. medRxiv. https://doi.org/10.1101/2020.04. 09.20049924

22. Frontera A, Martin C, Vlachos K, Sgubin G (2020) Regional air pollution persistence links to COVID-19 infection zoning. J Infect 81:318-386

23. Arbex MA, Santos Ude P, Martins LC et al (2012) Air pollution and the respiratory system. J Bras Pneumol 38(5):643-655

24. Xing YF, Xu YH, Shi MH, Lian YX (2016) The impact of PM 2.5 on the human respiratory system. J Thorac Dis 8(1):E69-E74

25. Zhou P, Yang XL, Wang XG et al (2020) A pneumonia outbreak associated with a new coronavirus of probable bat origin. Nature 579:270-273
26. Riccò M, Ranzieri S, Balzarini F et al (2020) SARS-CoV-2 infection and air pollutants: correlation or causation? Sci Total Environ 734:139489

27. Cox LA Jr, Popken DA (2020) Should air pollution health effects assumptions be tested? Fine particulate matter and COVID-19 mortality as an example. Glob Epidemiol. https://doi.org/10. 1016/j.gloepi.2020.100033

Publisher's Note Springer Nature remains neutral with regard to jurisdictional claims in published maps and institutional affiliations. 